\author{
Alyaa H. Mohammed \\ University of Technology \\ Civil Engineering \\ Department, Baghdad, Iraq \\ 40204@uotechnology.edu.iq
}

\section{Qais A. Hasan}

University of Technology

Civil Engineering

Department, Baghdad, Iraq

\author{
Kaiss F. Sarsam \\ University of Technology \\ Civil Engineering \\ Department, Baghdad, Iraq
}

Received on: 10/03/2019

Accepted on: 15/06/2019

Published online: 25/12/2019

\title{
Influence of Steel Fiber and Spacing of Stirrups on the Torsion Capacity of Hybrid Beams
}

\begin{abstract}
This paper investigates experimentally the torsional behaviour of hybrid reinforced concrete beams composed of reactive powder concrete (RPC) at the outer edges of the cross-section and conventional concrete (CC) at the inner parts of the cross-section. Hybrid reinforced concrete members are used extensively to deal with the members strength requirements related to flexural, shear and torsion in structural systems. The torsion failure is undesirable because of its brittle nature, it is obligatory to avoid this kind of failure in the earthquake areas. Seven reinforced concrete beams, with dimensions $(100 X 200 X 1500 \mathrm{~mm})$, the interior dimensions of hybrid beams of the cross-sectional area $(20 \mathrm{~mm}$ width and $120 \mathrm{~mm}$ height) with $1500 \mathrm{~mm}$ length were cast and tested to failure using two opposite cantilevers steel arms that contribute to transferring the torque to the centre of the beam. The first beam was RPC, the second beam was CC and the other five beams were all poured as hybrid ones. Experimental data of the ultimate capacity, cracking torsional loads, the failure pattern and twisting angle for each beam were gained. Experimental results showed higher value of ultimate torsional strength of hybrid beams than CC ones by about (50) \% and lower than reactive powder concrete specimen by about (16.67) \% for both varying steel fibre and spacing of stirrups.
\end{abstract}

Keywords- Conventional concrete, Hybrid concrete, Reactive powder concrete, Steel fibre.

How to cite this article: A. H. Mohammed, Q. A. Hasan and K.F. Sarsam, "Influence of Steel Fiber and Spacing of Stirrups on the Torsion Capacity of Hybrid Beams," Engineering and Technology Journal, Vol. 37, Part A, No. 12 , pp. 506-511, 2019.

\section{Introduction}

Recently hybrid reinforced concrete structures gained great interest by engineers due to their lower cost and good performance under loading. To explain the concept of the hybrid concrete section, a specific type of concrete in a specific zone of the section was used [1]. For shear, bending and torsion hybrid beams proved to be quite successful, as well as less costly compared to RPC ones.

In the past few decades, considerable efforts of research were dedicated to the studies of the torsional behavior of concrete structural members. Several studies have been devoted to developing the analytical models to predict the distribution of elastic stress and strength limits of the concrete beams under torsion [2]. There are many different structures where torsional loading could be a significant loading condition. The most noticeable are bridges and spandrel beams, the shear stress developed in the beam flows around of the outside surface. Pure torsion is a twisting loading, with no axial, or lateral force. It is also possible to have a pure torque loading on a beam.

A pure torque is two parallel but opposite separated forces of equal magnitude. It can be applied or reacted anywhere on a rigid body and have the same effect [3].

\section{Experimental Program}

Two mixes were used in this work: CC and RPC. Seven beams were cast as follows: the first one was CC; ii) the second was RPC; and five hybrid ones with $40 \mathrm{~mm}$ RPC all around. The last three have varying stirrups spacing: $37.5 \mathrm{~mm}, 50 \mathrm{~mm}$, $75 \mathrm{~mm}$. The other three variable had different of steel fibre ratios (Vf\%) includes: $0.5 \%, 1 \%$, $1.5 \%$. With the other variables constant to compare and study properties of concrete subjected to torsion.

\section{Beams Details}

In this investigation seven torsion tests are reported. Of these tests, five are hybrid. The CC had a mix proportions of $(1: 1.5: 1.75: 0.5)$, (cement: sand: gravel: w/c) respectively, with $10 \mathrm{~mm}$ max size of coarse aggregate. The RPC had a mix proportions of $(1: 1: 0.25: 6 \%: 0.2)$ (cement: fine sand: silica fume: super plasticizer: $\mathrm{w} / \mathrm{c})$ with steel fibre ratio Vf\% $(0.5 \%, 1 \%, 1.5 \%)$ respectively. All beams were designed and cast with the same mixes, following the ACI $318 \mathrm{M}$ code [4]. The beams were designed with varying spacing of stirrups. Figures 1and 2 and Table 1, give details of all seven beams. In all beams the 
load is applied on steel plates with opposite arms to obtain the required torque.

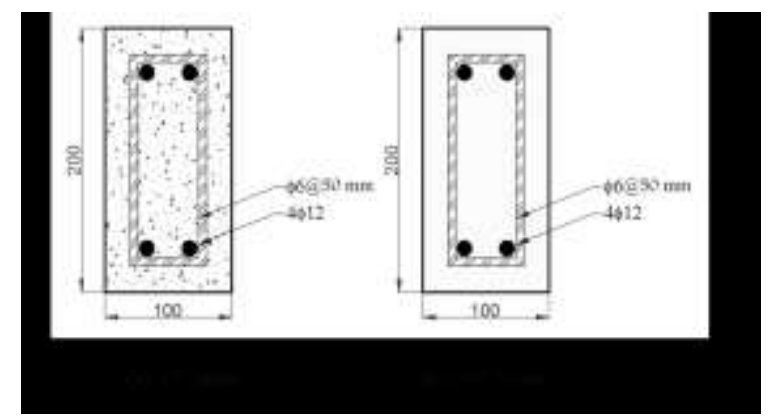

Figure 1: The CC beam and RPC beam.

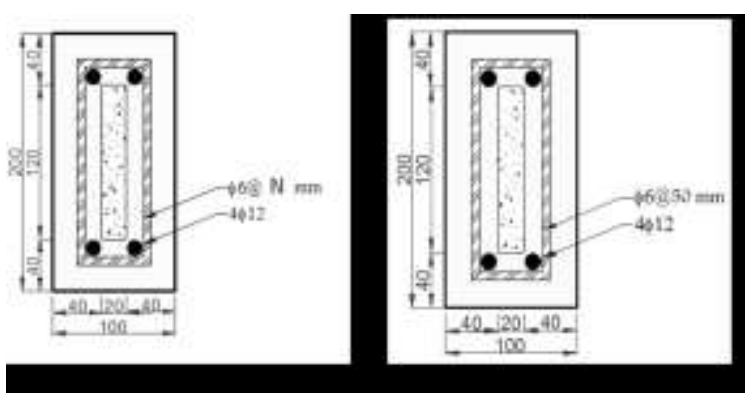

Figure 2: The hybrid beam with varying stirrups spacing $(\mathrm{N}=37.5,50$ and $75 \mathrm{~mm})$ and steel fibre ratio: $0.5,1$ and $1.5 \%$.

\section{Casting the hybrid beams}

The procedure for casting the beams was as follows: Firstly the first layer of RPC was cast in the bottom of the mould up to $40 \mathrm{~mm}$ of height, then two plates with $120 \mathrm{~mm}$ height were inserted inside the mould to separate the mixes, the second layer contains two types of concrete, the core with CC, $20 \mathrm{~mm}$, and the surrounding with RPC, $40 \mathrm{~mm}$, up to $160 \mathrm{~mm}$ of height. Finally, RPC mix was cast up to the top of the mould. As shown in the Figure 3. After 10 minutes, the plates were pulled out of the hybrid beams from the side of the mould.

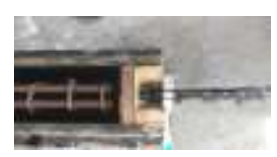

(a) the two plate inside the mold.

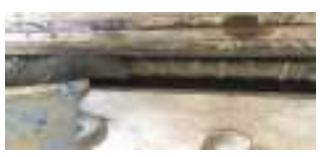

(b) $\mathrm{CC}$ in the core, RPC cast in the final layer.

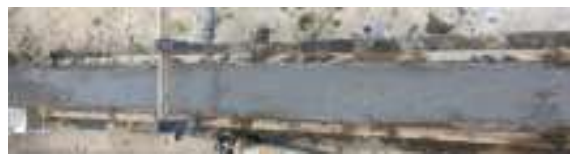

(c) Finally, the hybrid beams.
Figure 3: The procedure of casting the hybrid beams.

Table 1: Description of the tested beams

\begin{tabular}{llllll}
\hline \hline $\begin{array}{l}\text { Names of } \\
\text { Beams }\end{array}$ & $\begin{array}{l}\text { Concrete } \\
\text { type }\end{array}$ & $\begin{array}{l}\text { Longitudinal } \\
\text { reinforcement } \\
(\mathrm{Al}) \mathrm{mm}^{2}\end{array}$ & $\begin{array}{l}\text { Transvers } \\
\text { reinforcement } \\
(\mathrm{At}) \mathrm{mm}^{2}\end{array}$ & $\begin{array}{l}\text { Stirrups } \\
\text { spacing } \\
\text { mm }\end{array}$ & $\mathrm{Vf} \%$ \\
\hline $\mathrm{CC}$ & $\mathrm{CC}$ & 452.16 & 28.27 & 50 & 1 \\
\hline $\mathrm{RP}$ & RPC & 452.16 & 28.27 & 50 & 1 \\
\hline $\mathrm{H} 1$ & Hybrid & 452.16 & 28.27 & 50 & 1 \\
\hline $\mathrm{H} 2$ & Hybrid & 452.16 & 28.27 & 37.5 & 1 \\
\hline $\mathrm{H} 3$ & Hybrid & 452.16 & 28.27 & 75 & 1 \\
\hline $\mathrm{H} 0.5$ & Hybrid & 452.16 & 28.27 & 50 & 0.5 \\
\hline $\mathrm{H} 1.5$ & Hybrid & 452.16 & 28.27 & 50 & 1.5 \\
\hline
\end{tabular}

\section{Discussions of results}

\section{Compressive strength $\left(f^{\prime} c\right)$}

The compressive strength ( $\left.\mathrm{fc}^{\prime}\right)$ tests were carried out in accordance to ASTM [5] (100 mm diameter X $200 \mathrm{~mm}$ long). The average of three cylindrical specimens is used to determine compressive strength for $\mathrm{CC}$ mix at about (30.97 $\mathrm{MPa}$ ) and RPC mix Table 2 gives RPC details.

\section{Tensile strength (ft)}

The splitting tests were carried out in accordance to ASTM [6] (100mm diameter X $200 \mathrm{~mm}$ long), the average of three cylindrical specimens is used to determine splitting tensile strength for $\mathrm{CC}$ mix about $(2.86 \mathrm{MPa})$ and RPC mix given in Table 2 .

\section{Modulus of elasticity}

The modulus of elasticity tests were carried out in accordance to ASTM [7] (150mm diameter X $300 \mathrm{~mm}$ long), the average of three cylindrical specimens is used to determine the modulus of elasticity for CC mix (27900 MPa) and RPC mix given in Table 2.

Table 2: Properties of materials

\begin{tabular}{lllll}
\hline \hline $\begin{array}{l}\text { Name of } \\
\text { Beams }\end{array}$ & $\mathrm{Vf} \%$ & $\begin{array}{l}\text { Compressive } \\
\text { strength } \\
(\mathrm{MPa})\end{array}$ & $\begin{array}{l}\text { Splitting } \\
\text { tensile } \\
(\mathrm{MPa})\end{array}$ & $\begin{array}{l}\text { Modulus of } \\
\text { elasticity } \\
(\mathrm{GPa})\end{array}$ \\
\hline $\mathrm{H} 1$ & 1 & 86.35 & 10.43 & 49.34 \\
$\mathrm{H} 0.5$ & 0.5 & 65.94 & 8.47 & 38.1 \\
$\mathrm{H} 1.5$ & 1.5 & 93.71 & 12.04 & 56.75 \\
\hline
\end{tabular}




\section{$I V$. Steel reinforcement}

Two nominal deformed steel diameters, $6 \mathrm{~mm}$ was used as stirrup reinforcement at $37.5,50$ and $75 \mathrm{~mm}$ spacing and diameter $12 \mathrm{~mm}$ was used as flexural reinforcement. The details of bars are shown in Table 3.

Table 3: The details of bars

\begin{tabular}{lll}
\hline \hline $\begin{array}{l}\text { Nominal bar } \\
\text { diameter } \\
(\mathrm{mm})\end{array}$ & $\begin{array}{l}\text { Yield stress } \\
(\mathrm{MPa})\end{array}$ & $\begin{array}{l}\text { Ultimate } \\
\text { stress }(\mathrm{MPa})\end{array}$ \\
\hline 10 & 416.56 & 468.63 \\
12 & 516.20 & 617.15 \\
\hline
\end{tabular}

\section{Steel fiber}

Straight brass coated gold color short steel fibers $15 \mathrm{~mm}$ long with radius of $0.1 \mathrm{~mm}$ and aspect ratio of 75 and tensile strength $2600 \mathrm{MPa}$, according to the manufacturer [8].

\section{Cracking torsion capacity}

The cracking torsion is the load at which the tensile stress reaches at the beam the tensile strength of the concrete [9]. By its nature, cracking torsion is less precise than the ultimate torsion capacity-as the former may be influenced by observation. Table 4 shows the capacity of cracking torsion for all beams.

1) Spacing of stirrups: Three of the hybrid beams had the spacing reinforcement of $37.5 \mathrm{~mm}, 50 \mathrm{~mm}$ and $75 \mathrm{~mm}$ respectively. The cracking torsion was greater by $(19.86 \%)$ the same ratio with different spacing reinforcement when compared to the $\mathrm{CC}$ beam. On the other hand, the fully RPC beam had $(27.85 \%)$ greater cracking torsion than the CC beam. This work indicates that the hybrid beams are closer to the RPC one than the CC.

2) $\mathrm{Vf} \%$ : Three of hybrid beams had the $\mathrm{Vf} \%$ of $0.5 \%, 1 \%$ and $1.5 \%$ respectively. The cracking torsion was greater by $(19.86 \%)$ and $(43.84 \%)$ except beam H0.5 decreased (12.10\%) compared to the CC beam. On the other hand, the fully RPC beam had $(27.85 \%)$ greater cracking torsion than $\mathrm{CC}$ beam. Therefore, the hybrid beams were close to the RPC one than the CC beam.

\section{Ultimate torsion capacity}

The ultimate torsion capacity can be defined as the test machine reading when load drops [9] as deformation continues. Table 4 shows the ultimate torsion capacity for all beams.

1) Stirrups spacing: Three of the hybrid beams had the spacing reinforcement of $(37.5,50,75) \%$ respectively. The ultimate torsion was greater by $(51.43 \%),(50 \%)$ and $(18.1 \%)$ compared to the $\mathrm{CC}$ beam. On the other hand, the fully RPC beam had $(66.67 \%)$ greater ultimate torsion than the CC beam. Therefore, the hybrid beams were closer to the RPC one than the CC beam except beam H3 has $75 \mathrm{~mm}$ spacing stirrups. Decreasing stirrups spacing will increase the torsion capacity of the section, as shown in Figure 4.

2) $\mathrm{Vf} \%$ : Three of hybrid beams had the $\mathrm{Vf} \%$ of $(0.5,1,1.5) \%$ respectively. The ultimate torsion was greater by $(44.44 \%),(50 \%)$ and $(59.68 \%)$ compared to the $\mathrm{CC}$ beam. On the other hand, the fully RPC beam had $(66.67 \%)$ greater ultimate torsion than the $\mathrm{CC}$ beam. Therefore, the hybrid beams (all three) were closes to the RPC one than the $\mathrm{CC}$ beam.

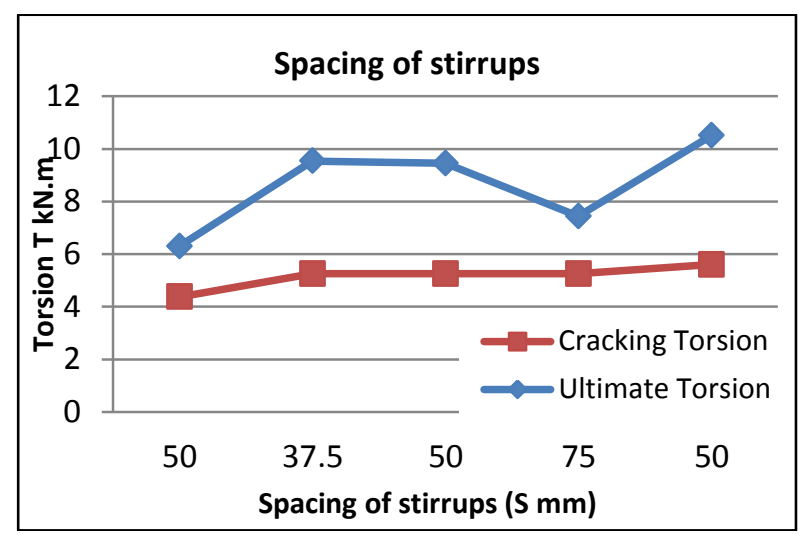

Figure 4: The capacity of cracking and torsion with varying stirrups spacing.

*50 at the first represented CC beam, at the end RPC beam and in the middle the Hybrid beam.

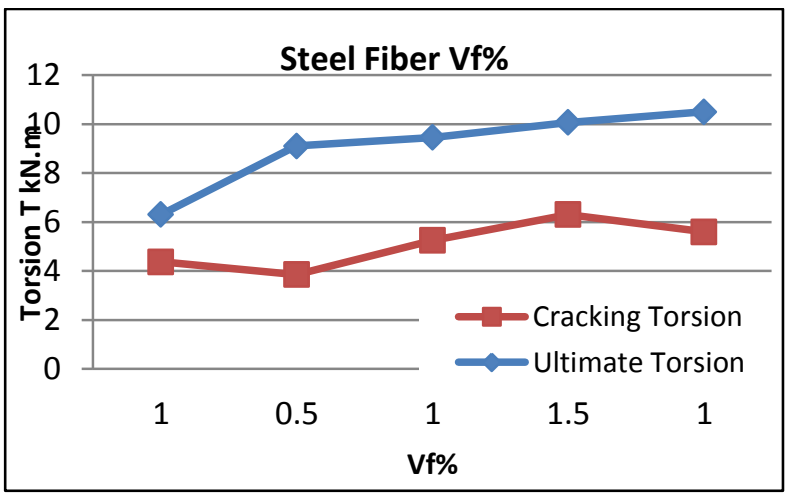

Figure 5: The capacity of cracking and torsion with varying steel fiber ratio $\mathrm{Vf} \%$.

Decreasing spacing of stirrups in hybrid beams led to ratios of increasing ( $\mathrm{Tu} / \mathrm{Tcr}$ ), except $\mathrm{H} 3$ beam has maximum spacing almost equal to $\mathrm{CC}$ beam (NC). As this percentage increases, the safety of concrete installations increases, as shown in Figure 6. But when increased the steel fibre ratio $\mathrm{Vf} \%$ decreased $(\mathrm{Tu} / \mathrm{Tcr})$, but this amount remains higher $\mathrm{CC}$ beam (NC) as shown in Figure 6. 


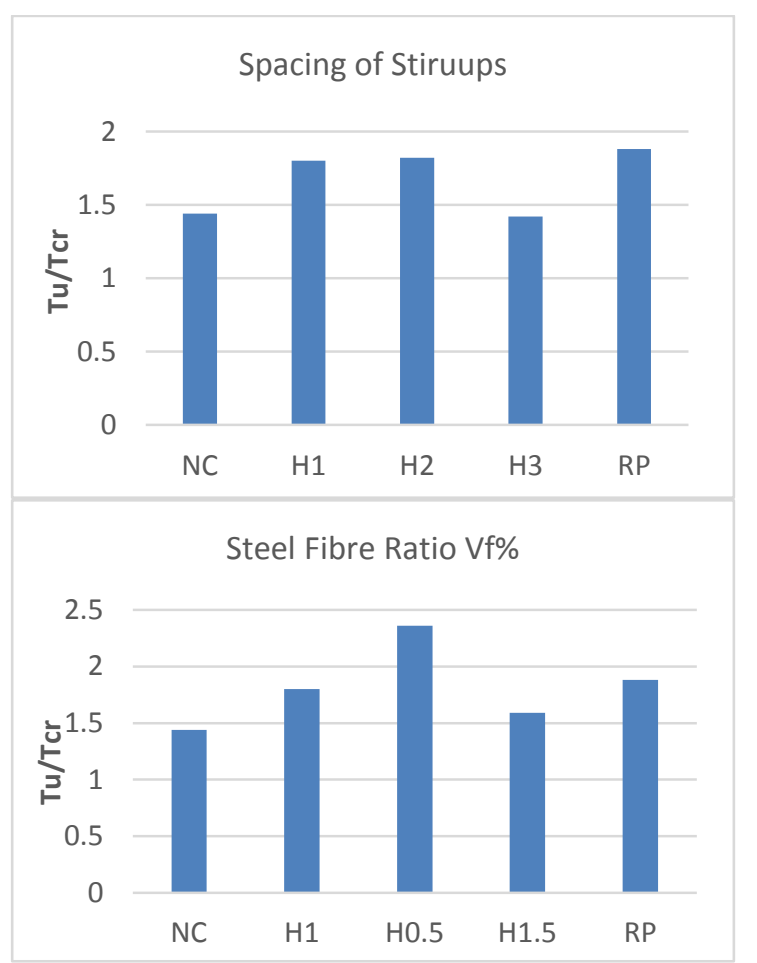

Figure 6: (Tu/Tcr) with all beams

\section{Angle of twist}

This is the angle through which the fixed end of a beam rotates with respect to the free end. The twisting of a body by the exertion of force tending to turn one end or part about a longitudinal axis while the other is turned in the opposite direction.

For the measurement of the angle of twist two LVDTs were attached to the plate steel in the end of beams, Figure 7. The $\mathrm{CC}$ beam (NC) reached maximum torque of (6.30) $\mathrm{kN} . \mathrm{m}$ at maximum rotation $(0.029) \mathrm{rad} / \mathrm{m}$. While the first cracking torsion was (4.38) kN.m at rotation $(0.025) \mathrm{rad} / \mathrm{m}$, beam had larger angle of twist with spurt failure. The RPC beam (RP) had rotation of ( 0.008 and $0.109) \mathrm{rad} / \mathrm{m}$ at cracking and ultimate torsion capacity respectively. Figure 8 shows that the hybrid beams ( $\mathrm{H} 1, \mathrm{H} 2$ and $\mathrm{H} 3$ ) are closer to the full RPC beam than the CC one. Figure 9 shows that the hybrid beams are closer to the full RPC beam, with $\mathrm{H} 0.5$ slightly less close.

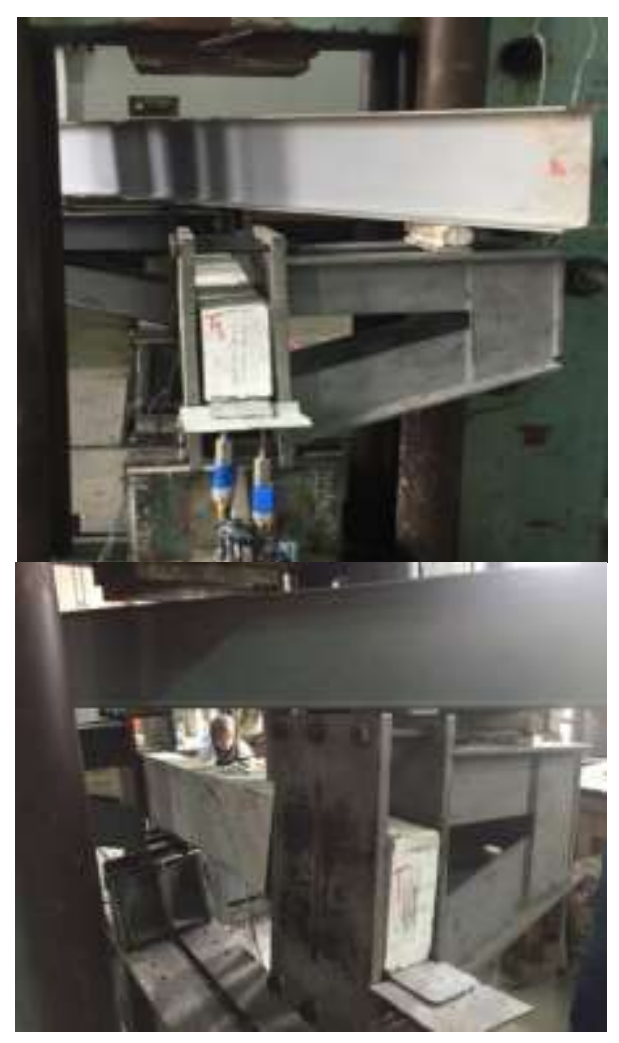

Figure 7: Show the LVDT and steel arms.

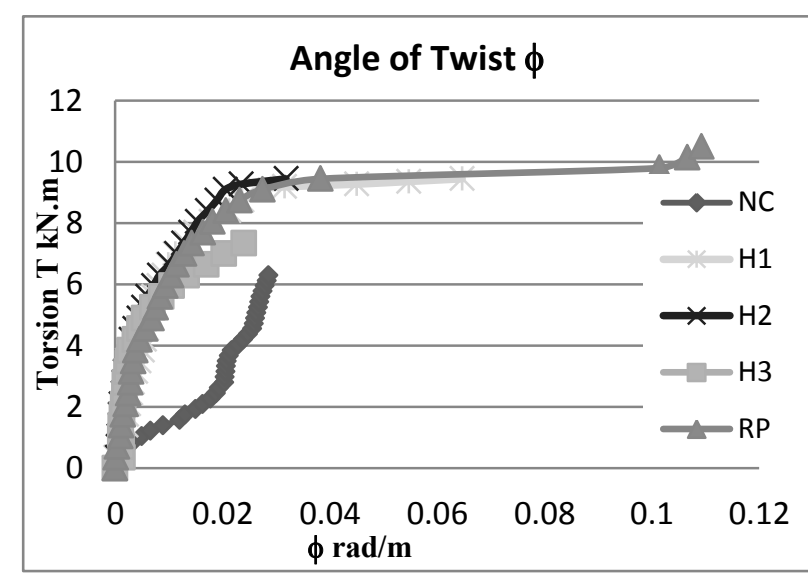

Figure 8: Angle of twist versus stirrups spacing

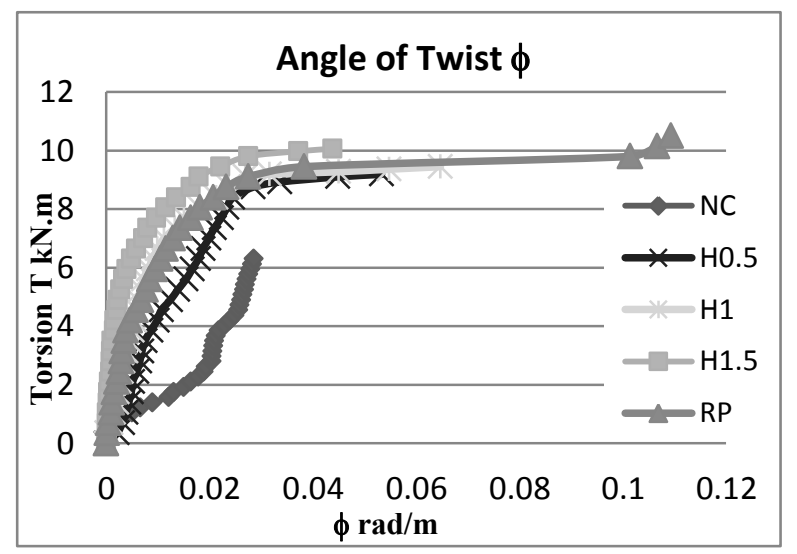

Figure 9: Angle of twist versus changing steel fibre ratio $V f \%$ 
Table 4: The cracking and ultimate torsion capacity

\begin{tabular}{lllllll}
\hline \hline $\begin{array}{l}\text { Name } \\
\text { of } \\
\text { beams }\end{array}$ & $\begin{array}{l}\text { Cracking } \\
\text { torsion } \\
\text { kN.m }\end{array}$ & $\begin{array}{l}\text { Ultimate } \\
\text { torsion } \\
\text { kN.m }\end{array}$ & $\begin{array}{l}\text { Percentage of } \\
\text { increase } \\
\text { ultimate torsion } \\
\text { \% (stirrups) }\end{array}$ & $\begin{array}{l}\text { Percentage of } \\
\text { increase } \\
\text { ultimate torsion } \\
\text { \% (stirrups) }\end{array}$ & $\begin{array}{l}\text { Angle } \\
\text { of twist } \\
\text { rad/m } / \mathrm{m}\end{array}$ & Tu/Tcr \\
\hline NC & 4.38 & 6.30 & - & - & 0.029 & 1.44 \\
H1 & 5.25 & 9.45 & 50.00 & 50.00 & 0.065 & 1.80 \\
H2 & 5.25 & 9.54 & 51.43 & - & 0.032 & 1.82 \\
H3 & 5.25 & 7.44 & 18.10 & - & 0.024 & 1.42 \\
H0.5 & 3.85 & 9.10 & - & 44.44 & 0.053 & 2.36 \\
H1.5 & 6.30 & 10.06 & - & 59.68 & 0.044 & 1.59 \\
RP & 5.65 & 10.50 & 66.67 & 66.67 & 0.109 & 1.88 \\
\hline
\end{tabular}

\section{Testing Procedure and Failure of Beams}

All beams including the control specimens were removed from water curing after 60 days. Drying lasted about 30 days, then all have been cleaned and painted white in order to obtain clear observation of cracks and their spread patterns. Steel arms were placed at both ends of each beam in opposing ways. A load has been applied. with load increment (at low loads), hairline cracks have formed in the areas between supporting arms. with further increase in load, multiple cracks with wider propagation began to form in diagonal orientation. These cracks continued to propagate with increasing load until reaching the failure point.

All tested beams failed in torsion as the inclined cracks were about 45 degrees to the beam axis. This cracking angle appeared in the surface of beams led to redistribution of internal stresses. The failure in NC beam was beyond just cracking and reached to crushing into cover concrete, which is more dangerous than the other beams at failure. In all six other beams failure is represented by cracks on the surface of the beams. Thus, hybrid beams are more reliable in terms of failure which is less catastrophe. The beams NC, H1, H2, H3, H0.5, H1.5 and RP are shown in Figure 10.

\section{Conclusion}

A total of seven beams were tested under the effect of pure torsion, in order to determine the effect of the spacing of stirrups and steel fibre ratio Vf\% on the strength of beams. Comments are given below:

1.Two mix procedures are used in this research presenting a successful way to produce hybrid beams with different reinforcement. 2.Unlike practically all codes (except the BS code [10]), this work indicates that concrete strength has a significant influence on torsional strength.
3.In general, the cracking and ultimate torsion capacity in hybrid beams are larger than $\mathrm{CC}$ and only slightly less than RPC beam.

4.The angle of twist decreased in hybrid and RPC beams when compared with normal concrete beam $(\mathrm{NC})$.

5.In CC beam the failure was beyond just cracking and reached to crushing into cover concrete, which is more dangerous than the other beams at failure. In contrast other beams failure led to cracks on the surface of the beams. Thus, hybrid beams are more reliable in terms of failure and economy.

6.In the hybrid beam (H0.5) has contained the lowest ratio of steel fibre $\mathrm{Vf}=0.5 \%$ that cracks began before they occurred in a CC beam (NC) but the final ultimate torsion was more than the $\mathrm{CC}$ by about $44.44 \%$. This indicates that the hybrid beams are safer than the CC beam.

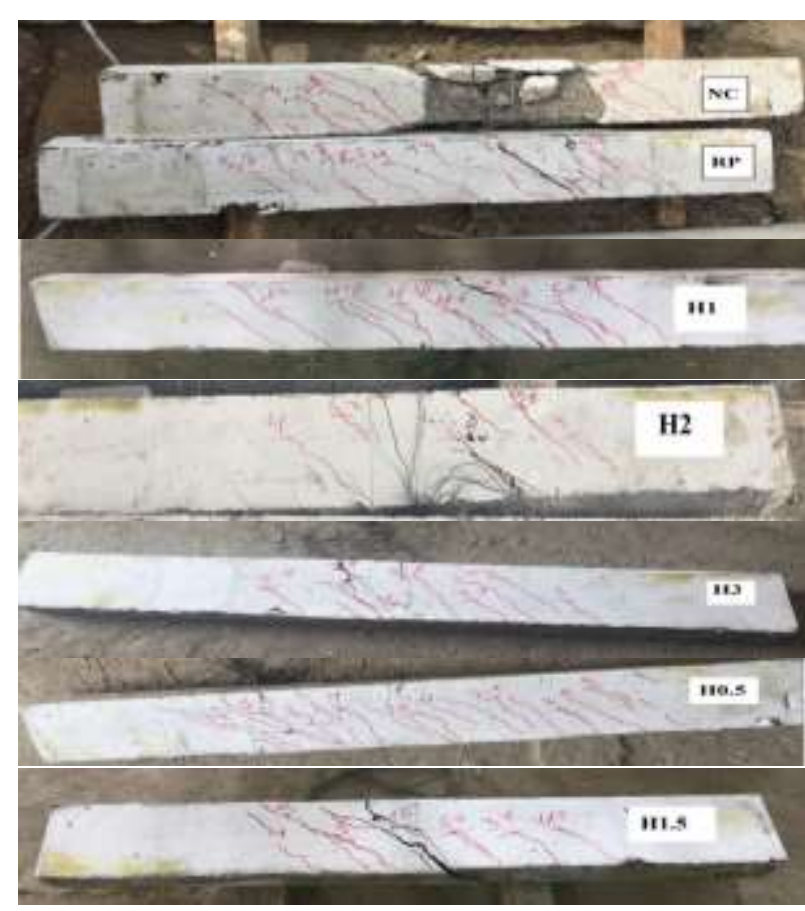

Figure 10: The Hybrid Beams 


\section{References}

[1] AM. Jassim, "Torsional Behavior of Hybrid reinforced Concrete Box Girders Composed of Conventional Concrete and Modified Reactive Powder Concrete," MSc. Thesis, Civil Eng. Dept., Univ. of ALMustansiryah, Iraq, 2017.

[2] J.R. Hillman, "Hybrid - Composite Beam (HCB) Design and Maintenance Manual," The Missouri Department of transportation. 27 Aug. 2012.

[3] S. M. AL-Zuabidi, "Strengthening of RPC Beams with External CFR in Torsion," MSc. Thesis, Civil Eng. Dept., Univ. of Technology, Iraq, 2016.

[4] ACI Committee 318, "Building code requirements for structural concrete (ACI318M) and commentary (ACI318RM)," American Concrete Institute, Michigan, USA, 2014.

[5] ASTM C 39/C39M-14, "Standard Test Method for Compressive Strength of Cylindrical Concrete Specimens," ASTM International, 100Barr Harbor Drive, west Conshohocken, United States, 2014.

[6] ASTM C496/C496M-11, "'Standard Test Method for Splitting Tensile Strength of Cylindrical Concrete Specimens," ASTM International, 100Barr Harbor Drive, west Conshohocken, United States, 2011.

[7] ASTM C 469/C469M-14, "Standard Test Method for Static Modulus of Elasticity and Poisson's Ratio of Concrete in Compression,' ASTM International, 100Barr Harbor Drive, west Conshohocken, United States, 2014.

[8] Hebei Yusen Metal Wire Mesh Co., LTd., (2018), Steel fibre quality certificate, available: http://www.chinasteelfiber.com.cn.

[9] R.S. Attea, "Torsional behaviour of reinforced concrete T-beams strengthened with CFRP strips," Case Studies in Construction Material, Vol. 7, pp 110-127, 2017.

[10] BS 8110 Code, "Structural Use of Concrete-Part 2," British standards, Institution, London, 1997. 